\title{
Apuntes sobre la historia y desarrollo del hip-hop en Costa Rica
}

Recibido: 22 de septiembre 2020 Revisado: 2 de junio 2021 Aprobado: 8 de julio 2021

Fabiola Palacios Murillo Costarricense. Licenciada en Trabajo Social y Bachiller en Historia del Arte, ambas por la Universidad de Costa Rica. Cuenta con estudios en Historia del arte y

Filosofía en la misma institución.

En el año 2018 fue investigadora

becaria del Programa Culturas,

instituciones y subjetividades del Instituto de Investigaciones

Sociales (IIS) de la Universidad de Costa Rica (Costa Rica). Actualmente es investigadora independiente y asistente de investigación en temas relacionados con arte contemporáneo y arte costarricense.

Correo electrónico:

palaciosm.fabiola@gmail.com

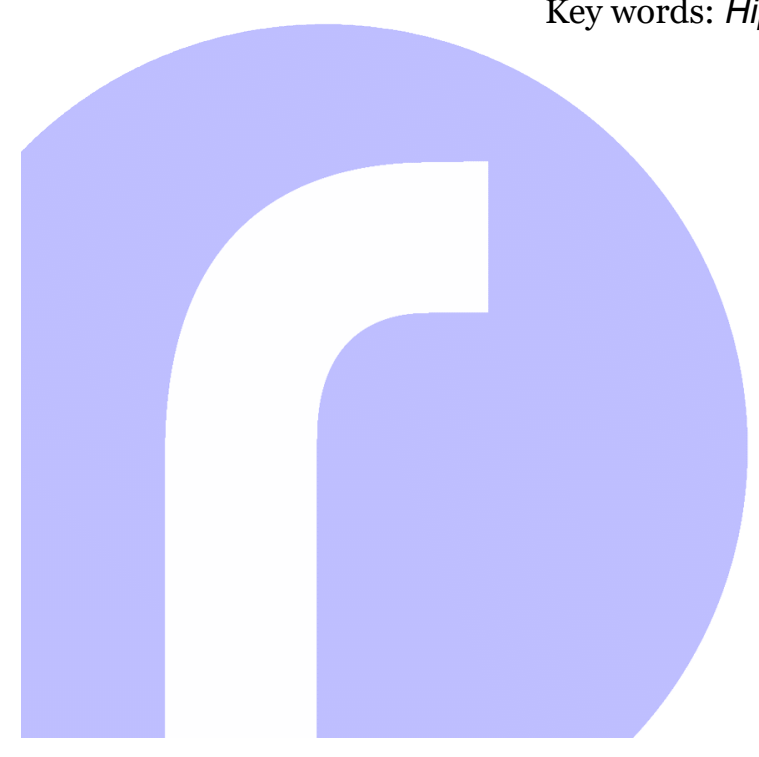

https://revistas.uned.ac.cr/index.php/rupturas cc) (i) (2)
Resumen: Este artículo tiene como objetivo analizar y discutir las condiciones históricas que marcaron el comienzo del hip-hop en Costa Rica, así como algunos acontecimientos que han particularizado la formación de una escena de hip-hop costarricense. La reconstrucción histórica se realizó a través de entrevistas a personas que fueron parte de este movimiento en sus inicios. La misma herramienta de investigación fue utilizada para caracterizar la escena hip-hop en la actualidad. El artículo explora algunas de las complejidades que han caracterizado el desarrollo del hip-hop en el país, el cual ha estado marcado por la colectivización, la autogestión, la competencia, la búsqueda de la autenticidad y una participación desigual con respecto al género.

Palabras clave: hip-hop, cultura, historia, identidad, música urbana

\section{Notes on the History and Development of Hip Hop in Costa Rica}

Abstract: This article aims to analyze and discuss the historical conditions that marked the beginning of hip hop in Costa Rica, as well as some events that have particularized the formation of a Costa Rican hip hop scene. The historical reconstruction was carried out through interviews with people who were part of this movement in its beginnings. This same research tool was used to characterize the hip hop scene today. The article explores some of the complexities that have characterized the development of hip hop in the country, which has been marked by collectivization, self-management, competition, the search for authenticity and unequal participation with respect to gender.

Key words: Hip hop, culture, history, identity, urban music 


\section{Introducción}

El hip-hop, entendido como un movimiento cultural que abarca cuatro elementos (grafiti, rap, breakdance y djing), surgió en la década de los setenta en Nueva York, Estados Unidos. Su expansión global se ubica a finales de ese mismo período, en 1979, cuando empezó su proceso de comercialización y difusión. El hip-hop es reconocido hoy en muchas partes del mundo y ha sido reapropiado en diferentes geografías, entre las que se encuentra Latinoamérica y en ella Costa Rica.

El primer cambio importante de esta relocalización es el lenguaje, pues pasa de ser producido en inglés y de asociarse con la cultura afroamericana estadounidense, a ser un producto flexible que en la actualidad se produce en diferentes idiomas y se mezcla con otras estéticas y manifestaciones culturales. El objetivo de este artículo es presentar los principales elementos que caracterizan la llegada del hip-hop a Costa Rica y su dinámica de transformación hacia la configuración de una escena de hip-hop costarricense.

Este artículo recoge algunos de los de hallazgos de la tesis de licenciatura titulada "Hip-hop en Costa Rica: discursos, prácticas y tensiones", finalizada en el año 2019. El enfoque de la investigación fue cualitativo y el proceso metodológico, al ser un tema sin antecedentes académicos en el país, consistió principalmente en entrevistas a personas clave, observación participante y entrevistas a artistas que se autodenominan parte de la escena hip-hop Costa Rica en la actualidad.

El término hip-hop, para efectos de este artículo, será comprendido de acuerdo a la propuesta del historiador estadounidense Jeff Chang (2014), quien realizó una reconstrucción de los principales acontecimientos económicos, políticos y sociales que dieron origen a este movimiento en Estados Unidos. Como se mencionó anteriormente, de acuerdo con esta perspectiva, el hiphop no es exclusivamente un género musical, sinoun conjunto de manifestaciones culturales que incluyen una forma de arte visual (grafiti), de música (rap y djing) y de danza (breakdance).

El contexto histórico en el que surge el hip-hop, así como su proceso de desplazamiento cultural, es fundamental para comprender su configuración y diferenciación en torno a otros procesos culturales o subculturas. Arlene Tickner (2007), sostiene que el hip-hop es tanto un mecanismo de afirmación cultural y de identidad colectiva, así como un instrumento para reflexionar sobre la marginalidad y ganar control sobre ella. Por esta razón, en muchos lugares el hip-hop ha sido apropiado por jóvenes de clase baja, en contextos marginalizados y con necesidad de replantear su identidad frente a los discursos del poder.

No obstante, tal y como se discutirá en este artículo, el hip hop ha sufrido históricamente una transformación mediada por la mercantilización y la industria 
cultural. Tal y como lo plantea Dick Hebdige (2004), esta subcultura inicialmente reclamaba una estética alternativa que se destacaba por el uso de ropa deportiva, pantalones holgados, gorras y tenis en contextos donde no necesariamente era permitido. Era contestataria en su discurso y en la manera en que se apropiaba de los espacios urbanos y producía alternativas a las narrativas acerca de las poblaciones afroamericanas y afrolatinas.

Para Hebdige (2004), la mercantilización de las subculturas supone su fin, pues deja su carácter contracultural y se convierte en otro producto del mercado. En el caso del hip-hop, es posible hallar esta ruptura con el surgimiento del gangsta rap, pues era un estilo que reproducía estereotipos étnicos y de género, además de hacer una apología al consumismo. Sin embargo, se podría decir que su huella de resistencia sigue latente en tanto que su producción en Latinoamérica y en este caso en Costa Rica, se fundamenta en la conceptualización de una serie de valores relacionados con una identidad de clase particular que continúa disputándose un lugar en la cultura local.

A continuación, se hará un recorrido por algunos elementos históricos, sociales y políticos que marcaron el contexto en el cual la juventud costarricense recibió la llegada del hip-hop.

\section{Los primeros años del hip-hop en Costa Rica}

De acuerdo con quienes incursionaron por primera vez en este movimiento, el hip-hop llegó a Costa Rica en los años ochenta. Para ese momento, la juventud costarricense parecía estar sufriendo un proceso de cambio. La década anterior había significado la articulación de fuerzas sociales y el surgimiento de vanguardias culturales y políticas (Molina y Palmer 2017). Uno de los más importantes acontecimientos, en cuanto a movimientos sociales, fue la lucha contra ALCOA ${ }^{1}$, de la cual participaron una gran cantidad de jóvenes costarricenses. La década nueva, por su parte, fue más bien el escenario de los inicios del neoliberalismo en el país, la crisis de la izquierda costarricense y una fuerte preocupación por despolitizar a las juventudes (Molina y Palmer 2017).

1. Este movimiento popular, que contó con una gran participación estudiantil, se originó a partir de la concesión que el gobierno del entonces presidente José Joaquín Trejos Fernández, dio a la empresa estadounidense Aluminum

En términos culturales, de acuerdo con Molina y Palmer (2017), con el go- Company of America (ALCOA), bierno de Rodrigo Carazo se produjeron importantes transformaciones. Se promovió un financiamiento tercerizado de la cultura, aparecieron centros educativos privados y el país sufrió un proceso de transnacionalización cultural que tuvo una amplia y rápida penetración en la vida cotidiana de muchas familias. Molina y Palmer (2017) señalan, por ejemplo, el aumento de la enseñanza del inglés en los colegios particulares, la creciente publicidad con estereotipos exportados de Miami, la aparición de tiendas para alquilar videos y la reubicación de cines locales y rurales a centros comerciales y "maIls", con películas provenientes en su mayoría de Estados Unidos.

A partir de 1981, un hito de la transformación cultural fue precisamente la introducción de la televisión (Molina y Palmer 2017), la cual va a tener posteriormente una gran influencia en el consumo cultural juvenil de la época. En 
2. Práctica de narración oral originada en África Occidental (Chang 2014).

3. Poesía recitada al ritmo del funk (Tijoux, Facuse y Urrutia 2012, 4).

4. Práctica que consiste en cantar sobre un ritmo musical, proviene también del griot.

5. Danza brasileña que se caracteriza por una conjunción de acrobacias y movimientos de tipo arte marcial.

6. Conocido popularmente como "baile del robot" en la costa oeste de Estados Unidos.

7. Una forma de danza alternativa a la confrontación física (Flores 1989).
1980 surgió Hola Juventud, un programa televisivo producido por el animador chileno Nelson Hoffman. Estaba dedicado a la difusión de videos musicales tanto nacionales como internacionales (Díaz 2018). El año coincide también con el surgimiento del canal MTV Music Television, aunque este era solamente transmitido por cable (Díaz 2018).

La creación de Hola Juventud, trajo consigo una serie de oportunidades para la música nacional, así como importantes cambios en la construcción identitaria de muchos y muchas jóvenes costarricenses (Díaz 2018). Cerca del año 1985 , se realizaron premiaciones y conciertos en diferentes partes del Valle Central (Díaz 2018). De esta época, se recuerda principalmente el desarrollo del chiqui-chiqui, que de acuerdo con Vargas (2015), fue un género musical popular creado a partir de la influencia de la música afrocaribeña y el calipso de la provincia de Limón (Vargas 2015, 54).

El chiqui-chiqui, el rock y el pop parecen haber sido los tres géneros musicales más sonados en la radio y con más transmisión en la televisión. Los tres tenían gran popularidad entre los jóvenes y las jóvenes a un punto que, de acuerdo con Vargas (2015), en el caso particular del chiqui-chiqui, al ser un género propiamente costarricense, las personas que se dedicaban a esta música, eran visualmente reconocibles en los videos musicales, se las consideraba "populares" y contaban con un cierto prestigio simbólico (Vargas 2015, 85-86). El programa Las estrellas se reúnen (Vargas 2015, 73), contemporáneo de Hola Juventud, tenía precisamente el objetivo de presentar a quienes conformaban las agrupaciones nacionales y darles un espacio de proyección para su música.

Contrario a lo que ocurrió con los tres géneros musicales anteriormente mencionados, el hip-hop al llegar al país, se posicionó como producto cultural alternativo y al margen del consumo popular de la mayoría de jóvenes en Costa Rica (Palacios 2019).

A continuación, se expondrán algunos aspectos fundamentales para comprender el desarrollo de este movimiento cultural y cómo fue apropiado en el país.

\section{Una cultura nacida en South Bronx, Nueva York}

El hip-hop está vinculado artística y estéticamente con una gran mezcla de sonidos, bailes y expresiones culturales que hacen de él, tal y como lo plantea Tickner (2007), un producto pluriétnico, pluricultural y diaspórico. Sus influencias se suelen encontrar en los sound systems en Jamaica (Chang 2014), en el griot ${ }^{2}$, el spoken word $^{3}$ y el toasting jamaiquino ${ }^{4}$ (Tijoux, Facuse y Urrutia 2012, 4). En el caso específico del baile, se suele enlazar con otras danzas como la capoeira ${ }^{5}$, el electro boogie ${ }^{6}$ (Tijoux et al 2012), la rumba, el guaguancó y el up-rock (Flores 1989).

Los cuatro elementos que se suelen asociar al hip-hop — graffiti, rap, breakdance y djing - tuvieron lugar por primera vez, en diferentes partes de la ciu- 
dad de Nueva York, en Estados Unidos. Creado por jóvenes afroamericanos/ as y latinoamericanos/as (Flores 1989), el hip-hop, entendido tanto como una subcultura o movimiento cultural, surgió como un espacio de resistencia ante las condiciones materiales de vida provocadas por el empobrecimiento, la exclusión social y el desplazamiento territorial de familias de inmigrantes vulnerabilizadas, en la década de los setenta en South Bronx, Nueva York (Chang 2014).

Esta "unión" de los cuatro elementos anteriormente mencionados, es producto de la fundación de la organización Universal Zulu Nation, por uno de los precursores de la cultura hip-hop, Afrika Bambaataa, en el año 1976. Su deseo era que lo que se conocería como hip-hop, tuviera una expresión gráfica, una de baile, otra de canto y otra de producción musical (Chang 2014). Para Bambaataa y quienes le seguían, existía además un quinto elemento llamado knowledge (conocimiento) (Chang 2014).

El hip-hop se expandió mundialmente a partir de la incursión del rap en la industria cultural. En el año 1979, se estrenó el sencillo Sugarhill Gang del grupo Rapper's Delight, que se convirtió en el éxito musical que logró trascender las fronteras de Estados Unidos (Chang 2014). Los ochenta fueron entonces el momento decisivo para la expansión del hip-hop. El grafiti artístico llegó a conocerse en 1982 con la película Wild Style, realizada por Charlie Ahearn y al año siguiente, con el documental Style Wars producido por Tony Silver, en

donde aparecían además las otras manifestaciones del hip-hop (Chang 2014). Aunque no completamente vinculada con el movimiento, la película Flashdance de 1983, dirigida por Adrian Lyne, dio a conocer pasos de baile que marcaban también la nueva influencia del baile urbano.

En 1984, las producciones audiovisuales sobre este nuevo movimiento cultural alcanzaron una gran expansión. Aparecieron las películas Beat Street dirigida por Stan Lathan y las dos partes de Breakin', del director Michael Boyd. Ambas fueron estrenadas en Costa Rica y visualizadas en cines nacionales. De acuerdo con Marlon Fadell (comunicación personal 27 de abril de 2018), precursor del breaking en Costa Rica, estas películas fueron parte de la cartelera de cines como Cine Capri, Cine Universal y Cine Metropolitan.

En el siguiente apartado, se expone la manera en que los cuatro elementos del hip-hop, fueron ingresando al país y animando a jóvenes costarricenses a crear las primeras producciones de hip-hop en Costa Rica.

\section{Hacia una escena local de hip-hop}

La llegada de los primeros productos culturales de hip-hop a Costa Rica estuvo marcada por tres factores fundamentales: a) el influjo cultural entre Estados Unidos, Limón y San José, b) el acceso a productos transnacionales a través de medios de comunicación como la televisión, la radio y el cine y c) la capacidad económica de tener un consumo cultural alternativo (Palacios 2019). 
8. El nombre de las dos agrupaciones denota ya la influencia de los productos culturales estadounidenses $y$ del idioma inglés.

9. La Unidad Preventiva del Delito fue una unidad policial que operó en el país hasta 1994.
El caso del breaking, que fue el primer "elemento" en desarrollarse en el país, está marcado por los primeros dos factores. Algunos videos musicales de hip-hop, tales como Buffalo Gals y Planet Rock, ambos de 1982, fueron transmitidos en el popular programa Hola Juventud (M. Fadell. comunicación personal 27 de abril de 2018). Las emisoras Radio Uno, Radio Juvenil y Estéreo Continental, a pesar de dedicar gran parte de su programación al rock y al pop, de vez en cuando daban espacio a otras manifestaciones culturales, entre las cuales se encontraba el hip-hop.

Marlon Fadell (comunicación personal 27 de abril de 2018), recuerda que los primeros videos musicales de hip-hop tuvieron un gran impacto especialmente por lo novedoso que parecía el baile. El popping, conocido en esa época como "electric boogaloo" (nombre probablemente adoptado a partir de la secuela de la película Breakin' 1), fue practicado por una gran cantidad de jóvenes hombres y mujeres, en diferentes salones de baile del país. Su popularidad fue tal que incluso se llegaron a realizar competencias (M. Fadell comunicación personal 27 de abril de 2018). No obstante, no ocurrió lo mismo con el breaking, el cual contó con menos participación y era principalmente practicado por jóvenes de los Barrios del Sur, Alajuelita, Cristo Rey y Barrio Cuba (M. Fadell comunicación personal 27 de abril de 2018), lo cual refleja una cierta vinculación de clase social desde el inicio.

Fadell (comunicación personal 27 de abril de 2018), recuerda que los espacios en donde se empezó a practicar el breakdance fueron la Plaza de la cultura, La Sabana, el Centro Omni y los barrios del sur. Como el baile requería de colocar las manos en el suelo, primero se ponían cartones o se enceraba el piso. Grupos de jóvenes, de aproximadamente 15 o 20 integrantes, se reunían para imitar los movimientos que habían visualizado en las películas y en los videos musicales (M. Fadell comunicación personal 27 de abril de 2018). Al ser un baile que requería gran destreza, los primeros interesados debían practicar mucho para poder lograr los movimientos.

En Estados Unidos, el breaking se practicaba grupalmente y a modo de competencia, por lo que el modelo fue trasladado de manera casi exacta a Costa Rica. En el país, las batallas eran llamadas "piques" y tenían como fin demostrarle al adversario quién podía bailar mejor, o bien disputarse un territorio (M. Fadell comunicación personal 27 de abril de 2018). De la época sobresalen en particular dos crews: Latin Crew Breakers y Breaking in control ${ }^{\beta}$.

Los años ochenta fueron escenario para el desarrollo de este baile, sin embargo, al igual que ocurrió en Estados Unidos, no tardó en encontrarse con obstáculos. Los bailarines, que según las personas entrevistadas eran en su totalidad hombres, debían enfrentarse a la policía y la Unidad Preventiva del Delito (UPD) ${ }^{9}$, que veían en este baile una práctica poco productiva para la juventud (M. Fadell comunicación personal 27 de abril de 2018).

La utilización de espacios públicos para realizar actividades artísticas y culturales autogestionadas, no era todavía una práctica común, por lo que, en ocasiones, quienes bailaban breakdance en la calle, eran movilizados por las 
autoridades. Fadell (comunicación personal 27 de abril de 2018) recuerda que el único espacio seguro era La Sabana, en donde podían pasar horas practicando sin interferir con otras actividades deportivas.

El final de los años ochenta marcó también el final de una etapa del breakdance en el país, los crews empezaron a ser más pequeños y quienes los conformaban, adquirieron nuevas responsabilidades vinculadas al mundo adulto (Palacios 2019). Esto no significó el final completamente, pero de acuerdo con Fadell (comunicación personal 27 de abril de 2018), pasó mucho tiempo para que volviera a activarse de la manera en la que estuvo antes.

Los noventa fueron el momento del rap, el cual se desarrolló gracias a una combinación entre el primer y el tercer factor; el influjo cultural entre Estados Unidos-Limón-San José y la posibilidad económica de acceder a productos culturales alternativos. La extracción de clase de quienes empezaron a practicar rap, fue bastante distinta a la de quienes empezaron en el breaking ( $\mathrm{Pa}-$ lacios 2019). El emceeing, nombre con el cual surgió el rap, fue practicado por jóvenes con un acceso mayor a recursos como la televisión por cable, viajes a Estados Unidos o Europa, educación en colegios privados y manejo del idioma inglés.

Durante esta época, el rap tuvo conexiones con otras manifestaciones culturales afrocaribeñas tales como el reggae y el dancehall, que hacían poco distinguible el público de uno u otro género (Palacios 2019, 76). Gustavo Guzmán (comunicación personal 13 de junio de 2018), uno de los primeros raperos del país, a finales de los años ochenta, recuerda haber desarrollado la técnica con su compañero de colegio Bryan Swett, a través de la imitación de las canciones que escuchaban en inglés.

La siguiente cita resume la experiencia primaria del rap en Costa Rica

Tomábamos los discos y los grabábamos en casetes.

Cuando queríamos hacer nuestro propio beat, era como conseguir el pedacito del beat en el disco de vinilo y ponerle pausa a tiempo para que llegue al otro pedacito, volverlo a reproducir y devolverle la aguja y devolverlo hasta que llegués a 4 minutos y medio, 3 minutos de lo mismo para después pasarlo de casete a casete [...]. Nos metíamos en el baño que como es encerrado, hace como eco y ahí grabábamos (G. Guzmán comunicación personal 13 de junio de 2018). 
El proceso era complicado y poco accesible, no cualquiera tenía acceso a herramientas para la grabación de música en la época. Sin embargo, en el año 1990, Guzmán y Swett conformaron La Pasa Tarasa, logrando grabar promociones cortas para Radio Uno y, la que sería probablemente la primera canción de rap costarricense, llamada "Rapicidio" (G. Guzmán comunicación personal 13 de junio de 2018). El sencillo trataba de una concientización acerca de las consecuencias negativas de los "piques" automovilísticos. Este tema musical tuvo incluso apoyo del Ministerio de Obras Públicas y Transportes (MOPT), quien solicitó a los jóvenes usar 30 segundos de la canción para difundir un mensaje de prevención ante la gran cantidad de accidentes ocurridos por estas prácticas.

La Pasa Tarasa participó como telonero del primer concierto internacional de rap en Costa Rica, organizado en el Palacio de los Deportes en Heredia (G. Guzmán comunicación personal 13 de junio de 2018). Ese día se contó con la participación de los grupos internacionales $C+C$ Music Factory y Mellow Man Ace. Pocos meses después, se dio el concierto del rapero estadounidense Vanilla Ice, quien tenía mucha presencia en la radio durante la época (Palacios 2019, 81).

Entrados los noventa, aparecieron varias agrupaciones de rap en el país. Prácticamente todas mezclaban los ritmos con el dancehall y el reggae. Eran en su mayoría, conformados por jóvenes afrodescendientes de San Francisco de Dos Ríos y de Desamparados (Palacios 2019, 79). Enoch Samuels (comunicación personal 17 de junio de 2018) y Huba Watson (comunicación personal 23 de mayo de 2018), precursores del rap en Costa Rica, comentan haber tenido contacto con el breaking desde sus infancias y con el rap en la época del colegio. Ambos fueron crearon diferentes agrupaciones en las cuales combinaban el rap con el baile.

En la época se crearon algunos grupos musicales tales como: Enjerod, VCR, Boombox, Juice y Natural Vibes. VCR, conformado por Enoch Samuels, Huba Watson, Patrick Skipton, Robert Barrett y Jeffrey Acosta, se presentó en el primer concierto internacional anteriormente mencionado y también, fue invitado a la inauguración del Centro Comercial Novacentro en Guadalupe, en el año 1992, lo cual les permitió grabar el primer sencillo llamado Sida, eso da, que hablaba de la expansión de ese virus en el país $(\mathrm{H}$. Watson, comunicación personal 23 de mayo de 2018).

A modo de imitación de las expresiones afroamericanas, las primeras canciones de hip-hop tocaban temáticas sociales que tenían como fin la sensibilización o la crítica social (Palacios 2019). De acuerdo con las fuentes consultadas, la mayoría de participantes, al igual que en el breakdance, fueron hombres. Sasha Campbell destaca por ser una de las primeras raperas costarricenses, quien conformó el grupo Natural Vibes junto a Enoch Samuels y Enrique Castillo. De acuerdo con su propio criterio, a pesar de que el hip-hop era claramente masculinizado, su participación como mujer nunca fue menospreciada (S. Campbell comunicación personal, 6 de junio de 2018). 
Ragga by roots, creado en 1996, fue uno de los grupos de rap y reggae más populares de la época. Conformado por Huba Watson, Frank Navarro (G Termis), Paco Jiménez y Robert Barrett, logró grabar con la disquera Disco Drama y colocarse en la escena de música nacional, siendo uno de los grupos más reconocidos de la época $(\mathrm{H}$. Watson comunicación personal 23 de mayo de 2018).

Todas estas primeras agrupaciones se enfrentaron a la dificultad de posicionar su música en los medios de comunicación, que en ese entonces tenían un papel fundamental en la configuración del consumo cultural juvenil. Como el rap no fue hegemónico ni masivo, la grabación de las canciones se realizaba a través de la autogestión y la cooperación colectiva.

El rap siguió desarrollándose en el país los siguientes años. Ya para finales de los noventa, se habían creado otros grupos como Squad, Doble sentido y Da' Crew. Además, el centro dejó de ser San José y aparecieron nuevas propuestas musicales en lugares como San Carlos, Puntarenas y Limón (Palacios 2019, 84).

El caso del djing y el grafiti en Costa Rica es particular pues ninguno de los dos estuvo inicialmente asociado con el hip-hop (Palacios 2019). El djing, surgió primero como una práctica vinculada a las discomóviles, por lo que es probable que haya comenzado en el país desde antes de la década de los ochenta. Para los noventa, algunos djs mezclaban hip-hop, pero no exclusivamente. De los cuatro elementos, al que era más difícil insertarse era este puesto que, tal y como lo plantea el dj de hip-hop Federico Peixoto (comunicación personal 18 de junio de 2018), conocido como Dj Gafeto, se necesitaba tener no solo la tornamesa, sino también los discos de vinilo, lo cual implicaba una importante inversión económica.

Tanto Federico Peixoto (comunicación personal 18 de junio de 2018) como Juan José Campos (comunicación personal 29 de junio de 2018), conocido como Dj Juan, experimentaron de forma autodidacta el scratching ${ }^{10}$. La si- 10. Técnica en la cual el disco guiente cita permite comprender los primeros acercamientos a esta práctica:

La parte de hacer la música y el sonido del scratch siemse manipula hacia adelante y hacia atrás creando un sonido particular.

pre me llamó mucho la atención, pero era como un misterio, no había nadie que hiciera eso y no había manera de aprenderlo, uno agarraba y trataba de hacerlo en las tornamesas de los papás y no son sistemas de faja, no se puede hacer para atrás entonces uno dañaba el disco y la tornamesa [...] entonces uno no entendía si las agujas eran especiales o los discos eran especiales o qué tipo de tornamesas, entonces por muchos años yo quise hacerlo, pero pasaron muchísimos hasta que de verdad ya 
11. Enrique Castillo

(comunicación personal 18 de abril de 2018) recuerda entre los primeros djs que mezclaban hiphop en estos lugares: Dj Beto, Dj Mike, Dj Element, Dj Kevin, Dj Richard, Dj Johnny, Dj Jason Lorenz y otros. pude empezar (Federico Peixoto, comunicación personal 18 de junio de 2018).

En términos generales, el djing era poco practicado y no exclusivamente vinculado al hip-hop, pues en los eventos, se solía mezclar también junto al reggae y el dancehall. Esto daba pie a que, nuevamente, las audiencias de estos otros ritmos musicales se combinaran con la del hip-hop (J. Campos, comunicación personal 29 de junio de 2018). Los djs ${ }^{11}$ se presentaban en salones de baile y discotecas, de las cuales se recuerdan por ejemplo Dynasty, Akelarre, All Star, DiNoiz y Casa Matute (Palacios 2019, 86-87).

A finales de la década de los noventa apareció por primera vez el grafiti, pero esta vez en asociación con otro movimiento urbano, el skateboarding (Palacios 2019). El grafiti como práctica política de resistencia, ya se realizaba en Costa Rica desde décadas atrás. Se rescata por ejemplo su papel fundamental en la anteriormente mencionada lucha contra ALCOA, en los años setenta. El de estilo artístico, por su parte, apareció en Costa Rica gracias a la influencia de grafiteros extranjeros como Kier Defstar de Estados Unidos y Chuck de Nicaragua (Villegas 2010). Ambos son considerados mentores de los primeros grafiteros costarricenses, entre los cuales se encuentran Mush y Hein (Villegas 2010).

De acuerdo con la investigación de Marialina Villegas (2010), el primer grafiti artístico aparece aproximadamente en el año 1996, en la Antigua Fábrica Bilsa. En este se leía la palabra "ESCORIA" y sus autores eran skaters. Los primeros espacios en donde se desarrolló el grafiti costarricense, fueron Curridabat, Montes de Oca y los Barrios del Sur. Los colectivos que se conocen de esta época son Unity Crew y PSK (F. Peixoto, comunicación personal 18 de junio de 2018).

De acuerdo con Peixoto (comunicación personal 18 de junio de 2018), hay un elemento particular que marca los inicios del grafiti en Costa Rica, y que lo diferencia de otros países de Centroamérica; a pesar de que esta es una práctica ilegal, la penalización hacia quienes lo practican es considerablemente menor a la de otros países centroamericanos. Esto podría estar relacionado también a que el grafiti en Costa Rica, parece estar más abocado hacia la crítica contra el consumismo y la publicidad (Emme, comunicación personal 12 de noviembre de 2018), por lo que las piezas aparecen en su mayoría en vallas publicitarias, cortinas de locales y otros muros con vinculación comercial y no necesariamente habitacional (Palacios 2019, 89).

Una discusión interesante en torno a este tema es señalada por Rahn (2002), quien señala que el grafiti produce debates en torno a la estética de la ciudad. Hay quienes lo defienden por ser una práctica que embellece el espacio público, y hay quienes lo interpretan como una práctica dañina y perjudicial. La autora señala que esto se asocia también con los valores simbólicos que tiene cada sociedad, pues, por ejemplo, para ciertas personas una pared 
blanca puede transmitir seguridad, mientras que el grafiti puede hacer referencia visual al conflicto, la violencia y el crimen contra la propiedad privada.

En Costa Rica, es probable que la recepción del grafiti se realice en ambas vías, así como también coexiste el graffiti artístico que se asocia con la técnica mural y es más aceptado socialmente, con otro grafiti ilegal que tiene como objetivo precisamente expresar de forma gráfica el conflicto que produce la imposición de un régimen estético en la ciudad, que aprueba ciertas imágenes y excluye otras.

Lo anterior es abordado en el trabajo de investigación de Marvin Rodríguez (2014), en donde sostiene que el grafiti artístico en Costa Rica se sitúa en zona ambigua, debido a que se mueve de forma dinámica entre la cultura popular, el arte, las industrias culturales y la instrumentalización de la cultura con fines políticos y de revitalización urbana (Rodríguez 2014, 226).

A partir de este breve recorrido histórico, en el siguiente apartado se pretende realizar un análisis de las condiciones y particularidades que configuran al hip-hop en Costa Rica.

\section{Apuntes sobre la escena actual de hip-hop costarricense}

Los últimos años han significado un incremento en la cantidad de personas que se autodefinen como parte de la escena hip-hop costarricense. El panorama actual es bastante distinto al anteriormente descrito. El acceso a internet, la amplificación de los medios de comunicación y la diversificación de las subculturas urbanas, ha transformado el funcionamiento de las diferentes escenas de música nacional.

De acuerdo con un análisis general en torno a las condiciones actuales del hip-hop en Costa Rica, la unidad de quienes conforman esta escena se base principalmente en una serie de discursos y prácticas que sostienen el sentido de comunidad y de pertenencia a la escena hip-hop (Palacios 2019). A continuación, se expondrán 4 factores clave para comprender el proceso identificación de quienes participan de la escena hip-hop en el país.

El primer factor que es necesario señalar es la unidad de los cuatro elementos - grafiti, rap, breaking y djing — que se da a través de una elaboración discursiva (Palacios 2019). El programa unificador propuesto por Afrika Bambaataa no es desconocido para quienes participan del hip-hop en Costa Rica. La mayoría se entiende como parte de una comunidad que tiene como meta unificarse (Palacios 2019).

El agrupamiento real de los elementos, no ha sido aún concretado. Sin embargo, sí pueden rastrearse esfuerzos unificadores en festivales, competencias, fiestas, entre otros. Hay interés en realizar eventos en donde exista participación de cada una de las manifestaciones culturales que conforman este movimiento. Sin embargo, es evidente que hay elementos, como el grafiti, que han tenido un desarrollo mucho más independiente (Palacios 2019). 
El segundo factor clave es la colectivización. En todas las expresiones de hip-hop excepto en el djing, hay interés en agruparse. De forma similar a como ocurría en Estados Unidos, cuando esta cultura inició, en el país hay también colectivos conocidos como crews, que representan no sólo un espacio de agrupación por intereses comunes, sino que es también una figura con fines prácticos (Palacios 2019). Los crews funcionan por ejemplo para que entre un grupo de artistas puedan retroalimentarse, intercambiar ideas, producir colaboraciones musicales o participar en competencias (Palacios 2019).

Las prácticas competitivas son fundamentales para el hip-hop desde que apareció en Nueva York. Djs, raperos, raperas, bailarines y bailarinas, acostumbraban competir en los llamados cyphers (Chang 2014). Mundialmente, la competencia en el hip-hop, pero especialmente en el rap, se ha convertido en un producto altamente comercializable y con mucha capacidad de aumentar las audiencias, por lo que, en los últimos años, ha tomado su propio camino a través de las batallas de rap.

Tanto la creación de colectivos como la competencia, constituyen puntos centrales para los procesos de producción de hip-hop. La competitividad llama la atención de las audiencias, por lo que es una oportunidad de comercialización del rap y del breakdance. Los colectivos o bien la creación de redes, permiten disminuir los costos económicos de la producción musical o audiovisual, la difusión mediante medios de comunicación y redes sociales, así como la realización de eventos culturales.

El tercer punto es la construcción identitaria, a partir de una idea clave para el hip-hop: "ser real" o "mantenerlo real". Esta frase, que se desprende de una variación en inglés "Keep it real", contiene en sí misma una construcción compleja acerca de quiénes pueden participar del hip-hop y cómo deben hacerlo. Arlene Tickner (2007), quien ha estudiado este concepto, menciona que hace referencia precisamente a la representación real de la vida cotidiana de la marginalidad, el empobrecimiento, la violencia y la discriminación.

Esta frase, que de acuerdo con Tickner (2007) estaría asociada con el surgimiento de cierto activismo anclado al hip-hop, sugiere que, en este movimiento cultural, lo importante es ser fieles a la realidad vivida, a las condiciones materiales de existencia y a la experiencia cotidiana desde la crudeza y la veracidad.

No obstante, con la expansión comercial del rap —que es el elemento en donde más se utilizan estas frases-, la noción de "ser real" adquirió nuevos matices y significados. Pueden, por ejemplo, estar relacionadas con la lealtad al barrio, con la negación de lo ficticio o performativo, o con una necesaria comprobación de la autenticidad del rapero o la rapera (Palacios 2019, 97).

Los procesos de identificación dentro del hip-hop, han tenido la necesidad de distanciarse de otros productos culturales asociados con la vida urbana y las poblaciones empobrecidas o vulnerabilizadas. Por ejemplo, a diferencia de los años noventa, cuando las audiencias de los géneros musicales provenientes del Caribe eran prácticamente la misma (J. Campos, comunicación 
personal 29 de junio de 2018), en la actualidad existe más bien un cierto rechazo por parte de quienes consumen hip-hop, hacia otras manifestaciones culturales como el reggaetón y el dancehall.

En términos generales, dentro de la escena de artistas asociados y asociadas al hip-hop, hay una búsqueda por mantener el sentido inicial con el cual este movimiento surgió en Nueva York (Palacios 2019). Esto ha tenido como resultado que, a diferencia de otros productos culturales, el hip-hop tenga una cierta identidad de clase que se traduce, al menos en algunas ocasiones, en resistencia a las dinámicas de la industria cultural y a la narratividad de las élites (Palacios 2019).

De igual manera, esta práctica según la cual hay una constante referencia a la historia y el origen del movimiento hip-hop, conlleva una mistificación de su propia historia, a través de la cual se ha establecido un "deber ser" del hiphop (Palacios 2019), resultando en posturas conservadoras o poco abiertas a los cambios culturales contemporáneos.

El último aspecto es la necesidad de comprender al hip-hop como un movimiento cultural masculinizado y en cierto sentido excluyente con respecto a las mujeres. La participación femenina dentro del hip-hop ha sido estudiada ampliamente por diversas autoras en Estados Unidos ${ }^{12}$, que reconocen que la introducción a este movimiento se ha dado precisamente desde un ámbito de resistencia y reivindicación. Si bien dentro del hip-hop hay una narratividad masculina, que refuerza los estereotipos de género y algunas ideas misóginas, las mujeres que se insertan en él, a pesar de los obstáculos, comúnmente se vinculan con discursos feministas o de reivindicación.

De acuerdo con Silva (2017), la inserción de las mujeres en el mundo del hiphop se puede interpretar como una ruptura con las relaciones de género, pues se requieren destrezas que no se suelen asociar con lo femenino. Esto incluye por ejemplo tomar espacios públicos para grafitear, salir tarde en la noche, producir crítica contra las autoridades o contra el sistema, participar en competencias, ocupar escenarios, apropiarse del micrófono, entre otros (Silva 2017).

En Costa Rica, la participación femenina es aún minoritaria con respecto a la de los hombres. No obstante, las mujeres han empezado cada vez más a incluirse en la escena de hip-hop y algunas también a agruparse de acuerdo a sus intereses colectivos y a resignificar un hip hop feminista que resiste a la exclusión y a los discursos misóginos que presentaban a las mujeres en el hip-hop solamente como objetos sexuales o acompañantes de los raperos (Palacios 2019).

\section{Reflexiones finales}

La llegada del hip-hop al país representó para un grupo de jóvenes, la oportunidad de pertenecer a un movimiento alternativo a la cultura difundida por la televisión y la radio en Costa Rica (Palacios 2019). Aunque nunca logró ser 
un movimiento masivo, despertó el interés de grupos de jóvenes que se enfrentaron a los medios de comunicación y construyeron nuevas propuestas para crear música y baile, a través de la colectividad y la autogestión.

En Costa Rica, el hip-hop se instaló por primera vez a través del baile, creando una conexión entre el cuerpo y la calle. Si bien se habla de una despolitización de las juventudes durante esta época (Díaz 2018), el breakdance era un baile de resistencia política que logró captar la atención de jóvenes que se encontraban en los sectores más populares de la sociedad. Aunque ya no había una ofensiva directa, el breaking permitió la apropiación de espacios públicos y la configuración de una identidad en un sentido clasista.

El surgimiento del rap en Costa Rica coincide con la aparición del gangsta rap en Estados Unidos, el cual es probablemente el estilo derivado que ha logrado obtener más popularidad en la industria cultural. Esto permite pensar que, en esa época, ya era mucho más sencillo reconocer a los artistas y las artistas, no sólo a través de unos cuantos videos musicales, sino por los discos. Para quienes empezaron a escuchar y producir rap en Costa Rica, fue importante el intercambio cultural con personas que venían de visitar otros países y que traían consigo productos que no era fácil conseguir (Palacios 2019).

Las diferencias de clase con respecto al acceso a los diferentes productos culturales, parece ser un punto clave para comprender el inicio de esta cultura en el país y también, para reflexionar sobre los discursos y prácticas que se han desplegado a partir de su desarrollo. El hip-hop es un producto cultural cada vez más popular y heterogéneo, pero, al mismo tiempo, dentro de su escena, hay posturas que se esfuerzan por distanciarlo de otros géneros musicales urbanos y por mantenerlo como un producto underground.

La escena de hip-hop costarricense parece estar expandiéndose cada vez más con el paso de los años. Sin embargo, se podría decir que este movimiento cultural se mantiene todavía en los márgenes de la cultura popular en Costa Rica. El rap es probablemente el elemento que más llama la atención de jóvenes y que se encuentra en una búsqueda por construir un estilo que trascienda la imitación y abra paso a una experimentación con matices más locales y regionales. Las batallas de rap, con sus complejidades, constituyen plataformas clave para promover o presentar nuevas propuestas musicales.

Uno de los puntos fundamentales que es importante considerar cuando se analiza el inicio del hip-hop en Costa Rica, es la poca participación femenina (Palacios 2019). Esto ha producido la necesidad de estudiar este movimiento cultural siempre desde un enfoque de género y contemplando las implicaciones que ha tenido que haya estado sido mayoritariamente conformado por hombres. Aún existen muchos retos con respecto a este tema, no solo porque se busca una mayor inclusión, sino por la importancia de reflexionar acerca de la narratividad que muchos artistas de hip-hop han construido en torno a las mujeres. 
Como último punto, rescato la importancia de profundizar en los inicios de otras manifestaciones culturales que acompañaron al hip-hop en este proceso de surgimiento, y también de estudiar las diferentes expresiones culturales desde un punto de vista regional que trascienda la Gran Área Metropolitana. Es fundamental que existan investigaciones que se direccionen hacia un estudio de la historia y el desarrollo del dancehall y el reggae en Costa Rica, los cuales tuvieron en algún momento una posición privilegiada dentro del ámbito de la música nacional costarricense.

\section{Referencias bibliográficas}

Chang, Jeff. 2014. Generación hip hop: de la guerra de pandillas y el graffiti al gangsta rap. Buenos Aires: Caja Negra Editora

Díaz, David. 2018. «Hijos de la crisis: la juventud costarricense de la década perdida (1978-1990)». En: La inolvidable edad: Jóvenes en la Costa Rica del siglo $X X$, editado por Iván Molina y David Díaz. Heredia: Editorial de la Universidad Nacional de Costa Rica.

Flores, Juan. 1989. «New York, Rap, Graffiti y Break». Debats 30: 100-103.

Hebdige, Dick. 2004. Subcultura: El significado del estilo. Buenos Aires: Paidós.

Molina, Iván y Steven Palmer. 2017. Historia de Costa Rica: breve, actualizada y con ilustraciones. San José: Editorial de la Universidad de Costa Rica

Palacios, Fabiola. 2019. «Hip hop en Costa Rica: Discursos, prácticas y tensiones». Tesis de licenciatura. Universidad de Costa Rica

Rahn, Janice. 2002. Painting without permission: hip hop graffiti subculture. Westport: Bergin \& Garvery

Rodríguez, Marvin. 2014. «Graffiti artístico en Costa Rica: una mirada sociológica». Tesis de licenciatura. Universidad de Costa Rica

Silva, Diana Alejandra. 2017. "Somos las vivas de Juárez": Hip hop femenino en Ciudad Juárez». Revista Mexicana de Sociología 79 (1): 147-174. https://www.redalyc.org/articulo.oa?id=32149150006

Tickner, Arlene. 2007. «El hip hop como red transnacional de producción, comercialización y reapropiación cultural». En: Redes transnacionales en la cuenca de los huracanes: un aporte a los estudios iberoamericanos, coordinado por Francis Pisani, Natalia Saltalamacchia, Arlene Tickner y Nielan Barnes. Ciudad de México: Instituto Tecnológico Autónomo de México y Miguel Ángel Porrúa. 
Tijoux, María Emilia, Marisol Facuse y Miguel Urrutia. 2012. «El Hip Hop: ¿Arte popular de lo cotidiano o resistencia táctica a la marginación?» Polis 11(33). https://journals.openedition.org/polis/8604

Vargas, Heriberto. 2015. «Transformaciones en el campo de la música popular bailable en Costa Rica en la década de 1985-1995». Tesis de licenciatura. Universidad de Costa Rica

Villegas, Marialina. 2010 «Apropiación del espacio público urbano a través del grafiti: los casos del Edificio Saprissa y Barrio La California en San José, Costa Rica». Tesis de licenciatura. Universidad de Costa Rica 